\title{
Assessment of Pesticide Residues in Tomatoes and Watermelons (Fruits) from Markets in Dar es Salaam, Tanzania
}

\section{*11JOHN A.M. MAHUGIJA; ${ }^{2}$ FARHAT A. KHAMIS; ${ }^{1}$ ESTHER H.J. LUGWISHA}

\author{
${ }^{1}$ Chemistry Department, University of Dar es Salaam, P.O. Box 35061 Dar es Salaam, Tanzania \\ ${ }^{2}$ Chief Government Chemist Laboratory Agency Zanzibar, Tanzania \\ "Corresponding author. Tel.: +255-222410038 \\ E-mail:mahugija@udsm.ac.tz; johnmahugija@yahoo.com
}

\begin{abstract}
This study investigated the levels of pesticide residues in selected fruits from major markets in Dar es Salaam city. Samples of tomatoes and watermelons were analysed for eighteen organochlorine, organophosphorus and pyrethroid pesticide residues. Extraction was performed using acetone followed by dichloromethane: cyclohexane mixture and the extracts were cleanedup using florisil. The compounds were determined by gas chromatography-mass spectrometry (GC-MS). Pesticides and metabolites were detected in $95.8 \%$ of the samples. The compounds detected included chlorpyrifos, $\alpha$-endosulfan, $\beta$-endosulfan and cypermethrin and their highest concentrations were $3810 \pm 50,370 \pm 20,120 \pm 6$ and $50 \pm 4 \mathrm{ng} / \mathrm{g}$, respectively. Others were $p, p^{\prime}$ $\mathrm{DDD}, o, p^{\prime}$-DDD, $p, p^{\prime}$-DDE and $\alpha-\mathrm{HCH}$ with highest concentrations varying from $1 \pm 0.5$ to $20 \pm$ $1.2 \mathrm{ng} / \mathrm{g}$. There were no significant variations in concentrations of the pesticide residues between the fruits and among the sampling sites, indicating similarities in contamination patterns. The concentrations of the contaminants were above the maximum residue limits (MRLs) in $41.7 \%$ to $50 \%$ of the tomatoes and watermelons indicating risks and concerns for public health. The Tanzanian agrochemicals and food regulatory agencies (e.g. TPRI, TFDA and TBS) and the government in general should ensure strict applications of laws that regulate pesticides in the country and develop effective educational programmes for farmers to apply good agricultural practices such as reducing the use of pesticides, applying appropriate pesticides and doses, and restrict the spray before harvesting. The consumers should thoroughly wash or process the fruits to reduce the levels. (C) JASEM
\end{abstract}

https://dx.doi.org/10.4314/jasem.v21i3.10

Keywords: Pesticides, Fruits, Food, Contamination, Tanzania

Pesticides are usually used in production of fruits (e.g. tomatoes and watermelons) because of their susceptibility to pests and diseases. Pesticides find their ways into the organisms through food, water and air. However, exposure to pesticide residues through the food is assumed to be five orders of magnitude higher than other exposure routes, such as air and water (Bempah et al., 2011). Fruits are normally eaten either fresh or semi-processed, which suggests that they may contain higher levels of pesticide residues compared to other food types of plant origins which are processed or cooked. Fruits containing residues of pesticides above the maximum residue limits may pose health hazards to the consumers (Sohair et al., 2013).

The amounts of pesticides used in Tanzania have been increasing annually. However, most farmers lack awareness regarding proper use of pesticides (Ngowi et al., 2007). Consequently, cases of indiscriminate use of pesticides and non-adherence to good agricultural practices are very common. For example, some farmers spray the fields in the afternoon and pick the fruits early in the next morning for selling in the local markets. These observations suggest that the fruits sold in the markets may have serious pesticides contamination. To the best of our knowledge, no study had been undertaken to assess pesticide residues in fruits in markets in Tanzania. The aim of this study was to investigate the levels and status of pesticide residues in selected favourite fruits (tomatoes and watermelons).

\section{MATERIALS AND METHODS}

Sampling: Fresh tomato (Lycopersicon esculenta) and watermelon (Citrullus lanatus) samples were collected from four major markets in Dar es Salaam city located at Mwananyamala, Temeke, Kariakoo and Buguruni. These markets are known for their massive sales of fruits that come from different areas of the country where pesticides are widely used. The samples were collected in January to February 2014, separately wrapped in aluminium foil, transported to the laboratory and kept in a refrigerator until extraction, which was conducted within 24 hours after sampling.

Sample extraction and clean-up: The sample was minced using a stainless steel knife and homogenized. The homogenized sample $(20 \mathrm{~g})$ was extracted with acetone $(30 \mathrm{~mL})$ by sonication in ultrasonic bath for $30 \mathrm{~min}$ and then with dichloromethane: cyclohexane $(1: 1,30 \mathrm{~mL})$ sonicated for $20 \mathrm{~min}$. The extract was filtered through glass wool, dried with anhydrous sodium sulphate, rinsed 
with dichloromethane: cyclohexane $(1: 1,5 \mathrm{~mL})$ and concentrated in a rotary evaporator at $40^{\circ} \mathrm{C}$ to $2 \mathrm{~mL}$. Clean-up of extracts was conducted using activated florisil $(3 \mathrm{~g})$ packed in a glass column $(10 \mathrm{~mm}$ i.d. $\mathrm{x}$ $32 \mathrm{~cm})$ and anhydrous sodium sulphate $(5-10 \mathrm{~cm})$ added on top. After rinsing the column with cyclohexane $(5 \mathrm{~mL})$, the extract $(2 \mathrm{~mL})$ was eluted with cyclohexane $(20 \mathrm{~mL})$ and cyclohexane: acetone (9:1, $10 \mathrm{~mL})$, concentrated in a rotary evaporator and made up to $2 \mathrm{~mL}$ in cyclohexane: acetone (9:1).

Analytical quality assurance: All the chemicals (solvents, reagents and pesticides standards) were of analytical grade and high purity (above 95\%). The glassware and tools were thoroughly cleaned with detergent and water and rinsed with distilled water and acetone. The calibration standards were stored in a freezer. Matrix and procedural blanks were analysed in every batch. Recovery (accuracy) tests involved spiking the standards into the matrix blank samples $(\mathrm{n}=8)$. The blank and recovery samples were processed and analysed using the same procedures as for the samples. Detection limits of the analytes were based on signals that were 3 times higher than the noise level (EC, 2015). No significant levels of contaminants were detected in the blank samples. The percentage recoveries of the analytes ranged from $72.4 \%$ to $112 \%$ with relative standard deviations of $<15 \%$; they were suitable (EC, 2015). The detection limits ranged from 0.1 to $0.6 \mathrm{ng} / \mathrm{g}$.

Analysis, identification, quantification and statistical analysis: The analyses were performed at Chemistry Department, University of Dar es Salaam using a GCMS equipped with an autosampler, capillary column (Rtx-5MS of $30 \mathrm{~m} \times 0.25 \mathrm{~mm}$ id x $0.25 \mu \mathrm{m}$ film) and MSD. The temperature programme was: $90^{\circ} \mathrm{C}$ held for $2 \mathrm{~min}$, then increased at $5{ }^{\circ} \mathrm{C} / \mathrm{min}$ to $260^{\circ} \mathrm{C}$ and held for $5 \mathrm{~min}$. Splitless injection of $1 \mu \mathrm{L}$ was carried out at $250{ }^{\circ} \mathrm{C}$ injector temperature with a purge flow of $3 \mathrm{~mL} / \mathrm{min}$. The carrier gas was helium, with flow rate of $2.17 \mathrm{~mL} / \mathrm{min}$ and the pressure was $150 \mathrm{kPa}$. The interface temperature was $300{ }^{\circ} \mathrm{C}$. The mass spectrometer ionization mode was electron impact (EI) with ion source temperature of $230{ }^{\circ} \mathrm{C}$ and in full scan mode in the range of $45-500 \mathrm{~m} / \mathrm{z}$. Standards were analysed at the beginning on each day of analysis. The compounds analysed were 14 organochlorines (aldrin, dieldrin, $\alpha$-endosulfan, $\beta$ endosulfan, $p, p^{\prime}$-DDT, $o, p^{\prime}$-DDT, $p, p^{\prime}$-DDD, $o, p^{\prime}-$ $\mathrm{DDD}, o, p^{\prime}-\mathrm{DDE}, p, p^{\prime}$-DDE, $\alpha-\mathrm{HCH}, \beta-\mathrm{HCH}, \gamma-\mathrm{HCH}$ and $\delta-\mathrm{HCH}), \quad 3$ organophosphorus pesticides (chlorpyrifos, fenitrothion and pirimiphos methyl) and 1 pyrethroid (cypermethrin). The compounds were identified by comparing their retention times and mass spectra in samples to those of standards and by using the NIST 11 mass spectral library. Quantification was done using peak heights and the calibration standards with concentrations of $0.5-2$ $\mu \mathrm{g} / \mathrm{mL}$. The mass fragment with the highest intensity was used for quantification. Statistical analysis of the data to test for significance of variations was performed using ANOVA (Analysis of Variance) and $t$-test (Motulsky, 1998).

\section{RESULTS AND DISCUSSION}

The retention times of the analytes detected in the samples were the same as those of standards (within a difference of $\pm 0.005 \mathrm{~min}$ in some cases) and their mass spectra had very high match factors. Typical mass spectra of some analytes are presented in Figure 1.

The tomato samples were found to contain $p, p^{\prime}$ DDD, $\alpha$-endosulfan, $\beta$-endosulfan, chlorpyrifos and cypermethrin and their detection frequencies were $91.7 \%, 50 \%, 50 \%, 41.7 \%$, and $33.3 \%$, respectively. Their concentrations are presented in Table 1 . The concentrations of $p, p^{\prime}$-DDD were generally low, with maximum of $11 \pm 9 \mathrm{ng} / \mathrm{g}$. The findings of $p, p^{\prime}$-DDD indicate its formation due to anaerobic degradation of $p, p^{\prime}$-DDT in the fruits or the environment. The concentrations of $\alpha$-endosulfan and $\beta$-endosulfan were up to $330 \pm 20 \mathrm{ng} / \mathrm{g}$ and $120 \pm 6 \mathrm{ng} / \mathrm{g}$, respectively and they did not exceed the MRL of 500 $\mathrm{ng} / \mathrm{g}$ (FAO/WHO, 2013). The concentrations of $\alpha-$ endosulfan were higher than of $\beta$-endosulfan, which indicated input of fresh technical endosulfan (ATSDR, 2013).

The concentrations of endosulfans are comparable to those found by Sheikh et al. (2013) in tomato samples from Sindh market in Pakistan, which ranged from nd to $680 \mathrm{ng} / \mathrm{g}$. A study in some fields in Tanzania found higher concentrations of endosulfan of up to 4150 $\mathrm{ng} / \mathrm{g}$ in tomato samples (Meela, 2009). Another study in fields in Tanzania found $p, p^{\prime}$-DDT, dieldrin, $\beta$ endosulfan, $\alpha-\mathrm{HCH}$ and $\gamma-\mathrm{HCH}$ in tomatoes at concentrations up to $0.62 \mathrm{ng} / \mathrm{g}$ (Mtashobya, 2010), which were lower than the concentrations found in this study.

Chlorpyrifos represented the highest concentrations in tomato samples, with concentrations up to $2340 \pm$ $60 \mathrm{ng} / \mathrm{g}$, which were 1.1 to 4.68 times greater than the MRL of $500 \mathrm{ng} / \mathrm{g}$ (FAO/WHO, 2013). These findings indicate potential risks and concerns for public health. Cypermethrin levels in tomato samples were up to $30 \pm 0.6 \mathrm{ng} / \mathrm{g}$ and were below the MRL of 200 $\mathrm{ng} / \mathrm{g}$. The levels of chlorpyrifos were greater than the levels found in tomatoes grown in Khyber Pakistan, which ranged from 310 to $1500 \mathrm{ng} / \mathrm{g}$, while the cypermethrin levels were lower than the levels found in Pakistan, which ranged from 60 to $1110 \mathrm{ng} / \mathrm{g}$ (Barkat et al., 2012). The field studies in Tanzania did not analyse or detect chlorpyrifos and cypermethrin in tomato samples. 

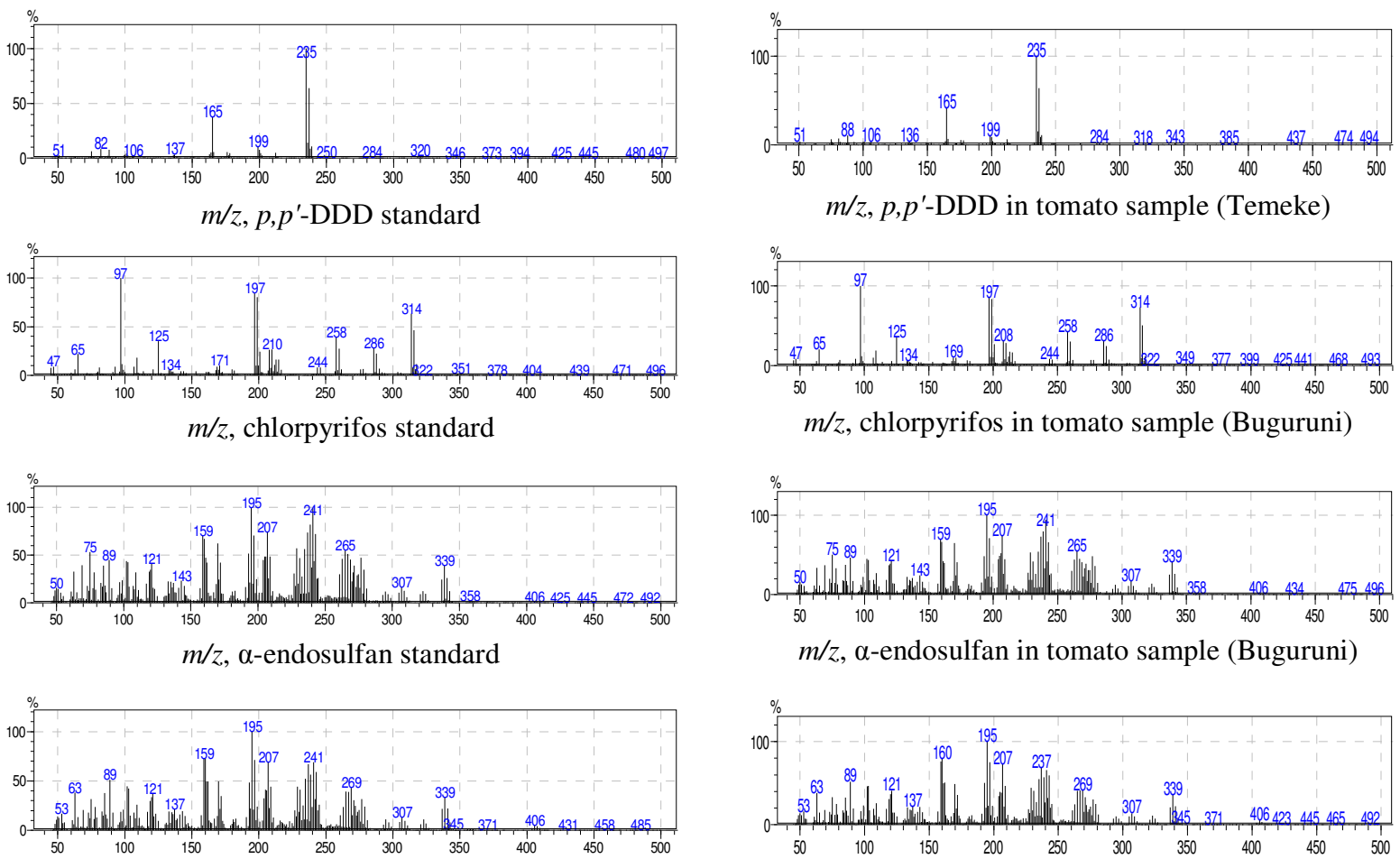

$m / z, \beta$-endosulfan standard

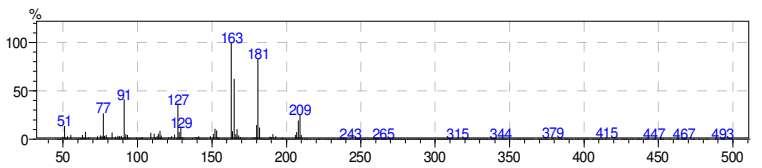

$m / z$, cypermethrin standard

$\mathrm{m} / \mathrm{z}, \beta$-endosulfan in watermelon sample (Kariakoo)

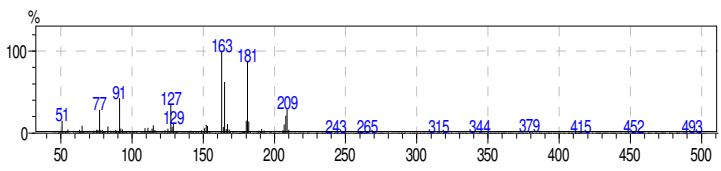

$\mathrm{m} / \mathrm{z}$, cypermethrin in watermelon sample (Buguruni)

Fig 1: GC-MS full scan mass spectra of selected analytes in standards and samples

Table 1: Concentrations of pesticide residues in tomato samples (ng/g)

\begin{tabular}{|c|c|c|c|c|c|c|}
\hline Site & Sample & $p, p^{\prime}$-DDD & $\alpha$-endosulfan & $\beta$-endosulfan & Chlorpyrifos & Cypermethrin \\
\hline \multirow[t]{3}{*}{ Kariakoo } & FT1 & $11 \pm 9.0$ & nd & nd & nd & nd \\
\hline & FT2 & $3.0 \pm 0.2$ & nd & nd & nd & nd \\
\hline & FT3 & $1.0 \pm 0.1$ & nd & nd & nd & nd \\
\hline \multirow[t]{3}{*}{ Buguruni } & FT4 & $7.0 \pm 0.4$ & $240 \pm 12$ & $90 \pm 4.0$ & $1950 \pm 50$ & nd \\
\hline & FT5 & $7.0 \pm 0.6$ & $260 \pm 13$ & $90 \pm 5.0$ & $2140 \pm 54$ & nd \\
\hline & FT6 & $1.0 \pm 0.02$ & nd & nd & nd & nd \\
\hline \multirow[t]{3}{*}{ Mwananyamala } & FT7 & $5.0 \pm 0.4$ & $190 \pm 10$ & $60 \pm 3.0$ & $530 \pm 20$ & $10 \pm 0.2$ \\
\hline & FT8 & $3.0 \pm 0.2$ & nd & nd & nd & $30 \pm 0.6$ \\
\hline & FT9 & nd & $110 \pm 6$ & $40 \pm 2.0$ & nd & nd \\
\hline \multirow[t]{3}{*}{ Temeke } & FT10 & $1.0 \pm 0.1$ & $310 \pm 20$ & $104 \pm 5.0$ & $1860 \pm 50$ & $10 \pm 0.2$ \\
\hline & FT11 & $1.0 \pm 0.01$ & nd & nd & nd & nd \\
\hline & FT12 & $1.0 \pm 0.2$ & $330 \pm 20$ & $120 \pm 6.0$ & $2340 \pm 60$ & $20 \pm 0.4$ \\
\hline
\end{tabular}

Concentrations expressed as mean \pm standard deviation of duplicates; $n d=$ not detected

Eight pesticide residues were detected in watermelon samples. Their concentrations are presented in Table 2 . The compound $p, p^{\prime}$-DDD was the most frequently detected (detected in $66.7 \%$ of the samples) but in low concentrations of up to $20 \pm 1.2 \mathrm{ng} / \mathrm{g}$. The concentrations of $p, p^{\prime}$-DDD were greater than those of $p, p^{\prime}$-DDE, indicating anaerobic degradation of DDT was favoured (ATSDR, 2002). The concentrations of DDT residues in all watermelon samples were below the MRL of $200 \mathrm{ng} / \mathrm{g}$ 
(FAO/WHO, 2013). The detection of $\alpha-\mathrm{HCH}$ in watermelons from only one site with concentrations of $4 \pm 0.4 \mathrm{ng} / \mathrm{g}$ indicated contamination from environmental sources. The $\alpha-\mathrm{HCH}$ concentrations were below the MRL of $10 \mathrm{ng} / \mathrm{g}$. The compounds $\alpha$ endosulfan and $\beta$-endosulfan were detected in $16.7 \%$ of the watermelons, with concentrations up to $370 \pm$ $20 \mathrm{ng} / \mathrm{g}$ and $120 \pm 5 \mathrm{ng} / \mathrm{g}$, respectively, which were below the MRL. Their proportions represented fresh technical endosulfan. Chlorpyrifos was detected in $50 \%$ of the watermelon samples and the maximum concentration of chlorpyrifos was $3810 \pm 50 \mathrm{ng} / \mathrm{g}$. The concentrations of chlorpyrifos in $41.7 \%$ of the samples were 1.79 to 3.81 times greater than the MRL of $1000 \mathrm{ng} / \mathrm{g}$ (FAO/WHO, 2013). Cypermethrin was detected in $33.3 \%$ of the watermelons with concentrations up to $50 \pm 4 \mathrm{ng} / \mathrm{g}$, which were below the MRL of $300 \mathrm{ng} / \mathrm{g}$ (FAO/WHO, 2013). The levels of chlorpyrifos were much greater than the levels found by Bempah et al. (2012) in watermelon samples from Accra markets in Ghana (3 $\pm 2 \mathrm{ng} / \mathrm{g})$.

Table 2: Concentrations of pesticide residues in watermelon samples (ng/g)

\begin{tabular}{|c|c|c|c|c|c|c|c|c|c|}
\hline Site & Sample & $\alpha-\mathrm{HCH}$ & $p, p^{\prime}-\mathrm{DDD}$ & $o, p^{\prime}-\mathrm{DDD}$ & $p, p^{\prime}-\mathrm{DDE}$ & $\alpha$-endosulfan & $\beta$-endosulfan & Chlorpyrifos & Cypermethrin \\
\hline \multirow[t]{3}{*}{ Kariakoo } & FW1 & $4.0 \pm 0.4$ & $4.0 \pm 0.2$ & nd & nd & nd & nd & nd & nd \\
\hline & FW2 & nd & $1.0 \pm 0.1$ & nd & nd & nd & nd & nd & nd \\
\hline & FW3 & nd & $10 \pm 0.6$ & $1.0 \pm 0.5$ & $2.0 \pm 0.7$ & $370 \pm 20$ & $120 \pm 5.0$ & $1880 \pm 60$ & nd \\
\hline \multirow[t]{3}{*}{ Buguruni } & FW4 & nd & nd & nd & nd & nd & nd & nd & nd \\
\hline & FW5 & nd & $20 \pm 1.2$ & nd & nd & nd & nd & nd & nd \\
\hline & FW6 & nd & nd & nd & nd & nd & nd & $2210 \pm 70$ & $17 \pm 2.0$ \\
\hline \multirow{3}{*}{$\begin{array}{l}\text { Mwana- } \\
\text { nyamala }\end{array}$} & FW7 & nd & $1.0 \pm 0.1$ & nd & nd & nd & nd & $3.0 \pm 0.1$ & $20 \pm 2.0$ \\
\hline & FW8 & nd & nd & nd & nd & $220 \pm 10$ & $80 \pm 3.0$ & $1790 \pm 50$ & nd \\
\hline & FW9 & nd & $1.0 \pm 0.3$ & nd & nd & nd & nd & $3810 \pm 50$ & $50 \pm 4.0$ \\
\hline \multirow[t]{3}{*}{ Temeke } & FW10 & nd & $14 \pm 1.0$ & $1.0 \pm 0.4$ & nd & nd & nd & nd & nd \\
\hline & FW11 & nd & $1.0 \pm 0.4$ & nd & nd & nd & nd & nd & nd \\
\hline & FW12 & nd & nd & nd & nd & nd & nd & $1910 \pm 60$ & $17 \pm 1.0$ \\
\hline
\end{tabular}

Concentrations expressed as mean \pm standard deviation; $\mathrm{nd}=$ not detected;

Generally, $95.8 \%$ of the samples contained pesticide residues. The detection frequencies of $p, p^{\prime}$-DDD and endosulfans were higher in tomatoes than watermelons. Chlorpyrifos had higher detection frequency in watermelons than in tomatoes. The occurrence of cypermethrin did not vary between tomatoes and watermelons, while $o, p^{\prime}$-DDD, $p, p^{\prime}-$ DDE and $\alpha-\mathrm{HCH}$ were detected in watermelons only. There were no significant differences in mean concentrations of the pesticide residues between tomatoes and watermelons $(t=0.4238-1.367,22$ degrees of freedom, $p=0.1855-0.6758)$, indicating similar applications or similar contamination patterns. No significant variations were found in the concentrations of pesticide residues among the sampling sites (tomatoes $F(3,59)=1.715, p=$ 0.1743 and watermelons $F(3,95)=0.4958, p=$ $0.6861)$. This indicated that the fruits from all the markets had similar sources.

Conclusion: The concentrations of some of the pesticide residues in samples were generally high with endosulfans and chlorpyrifos representing the highest levels and which indicated input of fresh technical products. The composition of the DDT residues indicated anaerobic degradation was favoured. The contamination patterns in both types of the fruits were similar. About $46 \%$ of the samples contained pesticide residues above the maximum residue limits, indicating health risks to the consumers. Effective controls and processing are required.
Acknowledgements: This study was supported by the Chief Government Chemist Laboratory Agency Zanzibar and the African Network for the Chemical Analysis of Pesticides (ANCAP).

\section{REFERENCES}

Agency for Toxic Substances and Disease Registry (ATSDR) (2002). Toxicological profile for DDT, DDE and DDD. U.S. Department of Health and Human Services.

ATSDR (2013). Toxicological profile for endosulfan. U.S. Department of Health and Human Services.

Barkat, AK; Ahmad, Z; Sher, AK; Zahoor, U (2012). Monitoring pesticide residues in fruits and vegetables grown in Khyber Pakhtoonkhwa. International Journal of Green and Herbal Chemistry 3: 302-313.

Bempah, CK; Buah-Kwofie, A; Denutsui, D; Asomaning, J; Tutu, AO (2011). Monitoring of pesticide residues in fruits and vegetables and related health risk assessment in Kumasi Metropolis Ghana. Research Journal of Environmental and Earth Sciences 3:761-771.

Bempah, CK; Asomaning, J; Boateng, J (2012). Market basket survey for some pesticides residues in fruits and vegetables from Ghana. The Journal of Microbiology, Biotechnology and Food Sciences 2: 850-871. 
FAO and WHO (2013). Pesticide residues in food and feed. Codex Alimentarius Commission, Joint FAO and WHO Food Standard Programme, Rome Italy.

EC (European Commission) (2015). Guidance document on analytical quality control and validation procedures for pesticide residues analysis in food and feed, Document No. SANTE/11945/2015 of 1 December 2015 Supersedes SANCO/12571/2013 of 19 November 2013, EC.

Meela, MM (2009). Assessment of types and levels of pesticide residues in some commonly grown vegetables in Tanzania. MSc Thesis, University of Dar es Salaam.

Motulsky, H (1998). GraphPad Software, InStat guide to choosing and interpreting statistical tests, GraphPad Software, Inc. San Diego California USA.
Mtashobya, LA (2010). Assessment of types and levels of pesticide residues in Western Usambara and Uluguru Mountains of Tanzania. MSc Thesis, University of Dar es Salaam.

Ngowi, AVF; Mbise, TJ; Ijan, ASM; London, L; Ajayi, OC (2007). Pesticides use by smallholder farmers in vegetable production in Northern Tanzania. Crop Protection 26: 1617-1624.

Sheikh, SA; Nizamani, SM; Panhwar, AA; Mirani, $\mathrm{BN}$ (2013). Monitoring of pesticide residues in vegetables collected from markets of Sindh, Pakistan. Food Science and Technology Letters 4: 41-45.

Sohair, AGA; Mohsen, MA; Mohamed, AA; Wasfi, MT (2013). Dietary intake of pesticide residues in some Egyptian fruits. Journal of Applied Sciences Research 9: 965-973. 